NASA Technical Memorandum 102622

\title{
Effects of Spoiler Surfaces on the Aeroelastic Behavior of a Low-Aspect-Ratio Rectangular Wing
}

\author{
Stanley R. Cole
}

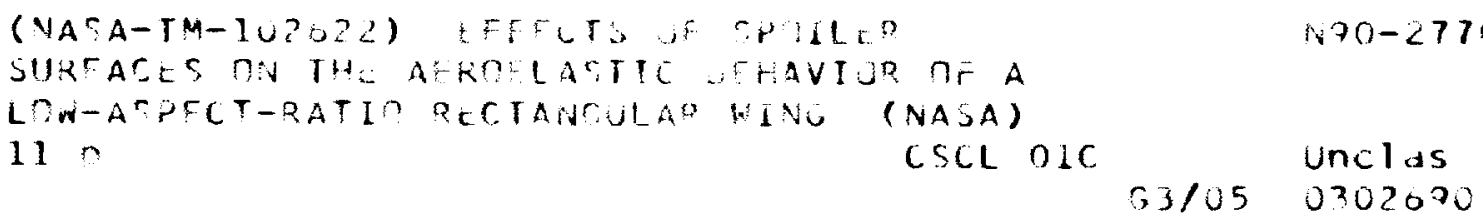

\section{NASA}

National Aeronautics and Space Administration 
$-$

. 


\section{EFFECTS OF SPOILER SURFACES ON THE AEROELASTIC BEHAVIOR OF A LOW-ASPECT-RATIO RECTANGULAR WING}

Stanley R. Cole

NASA Langley Research Center

Hampton, VA 23665-5225

\section{Abstract}

An experimental research study to determine the effectiveness of spoiler surfaces in suppressing flutter onset for a low-aspect-ratio, rectangular wing has been conducted in the Langley Transonic Dynamics Tunnel (TDT). The wing model used in this flutuer test consisted of a rigid wing mounted to the wind-tunnel wall by a flexible, rectangular beam. The flexible beam was connected to the wing root and cantilever mounted to the wind-tunnel wall. The wing had a 1.5 aspect ratio based on wing semispan and a NACA 64A010 airfoil shape. The spoiler surfaces consisted of thin, rectangular aluminum plates that were vertically mounted to the wing surface. The spoiler surface geometry and location on the wing surface were varied to determine the effects of these parameters on the classical flutter of the wing model. Subsonically, the experiment showed that spoiler surfaces increased the flutter dynamic pressure with each successive increase in spoiler height or width. This subsonic increase in flutter dynamic pressure was approximately 15 percent for the maximum height spoiler configuration and for the maximum width spoiler configuration. At transonic Mach numbers, the flutter dynamic pressure conditions were increased even more substantially than at subsonic Mach numbers for some of the smaller spoiler surfaces. But greater than a certain spoiler size (in terms of either height or width) the spoilers forced a torsional instability in the transonic regime that was highly Mach number dependent. This detrimental torsional instability was found at dynamic pressures well below the expected flutter conditions. Variations in the spanwise location of the spoiler surfaces on the wing showed little effect on Mutter. Flutter analysis was conducted for the basic configuration (clean wing with all spoiler surface mass properties included). The analysis correlated well with the clean wing experimental flutter results.

\section{Nomenclature}

c wing chord, $\mathrm{ft}$

E Young's modulus of elasticity, $\mathrm{lb} / \mathrm{ft}^{2}$ f

h

$\mathrm{h}_{\mathbf{S}}$

$\mathrm{M}$

q

$S_{h}$

$\mathbf{S}_{\mathbf{W}}$

V

w

$\mathbf{x}$

$\eta$

$\rho$ frequency, $\mathrm{Hz}$ vertical dimension between top and bottom spoiler outer edges, in vertical dimension of spoiler above (or below) the wing surface, in Mach number dynamic pressure, $1 \mathrm{~b} / \mathrm{ft}^{2}$

Strouhal number based on spoiler height dimension $=2 \pi \mathrm{fh} / \mathrm{V}$ Strouhal number based on spoiler width $=2 \pi \mathrm{fw} / \mathrm{V}$ velocity, in/sec spoiler width in the span direction, in streamwise distance from wing leading edge, $f t$ percent span measured from wing root density, slugs $/ \mathrm{ft}^{3}$

\section{Introduction}

Experimental aeroelastic wind-tunnel testing has always been risky in terms of model integrity due to the fact that aeroelastic instabilities, such as flutter or static divergence, often quickly destroy the model. Occasionally, such losses represent the only useful information obtained after a great financial and time investment has been made to explore an aeroelastic phenomenon. To make matters worse, the test facility is also at risk from the debris of a destroyed model. Many test techniques ${ }^{1}$, physical mechanisms ${ }^{2-4}$, monitoring techniques, and safety features 5,6 have been developed and are being developed when possible to reduce risks to both models and test facilities during aeroelastic testing.

One such technique which has been used recently on several aeroelastically scaled flutter models is a deployable spoiler surface intended to substantially disrupt the aerodynamic forces on the model and thereby prevent flutter. This report describes a research study which was undertaken to specifically examine the effectiveness of such surfaces in preventing flutter. The goal of the project was to obtain guidelines for locating and sizing such surfaces on models to maximize their effectiveness in suppressing flutter. The spoiler surfaces tested in this study were fixed in position and could not be remotely deployed as would be required for testing of an actual aeroelastic model. Identical spoiler surfaces were mounted above and below the wing surface at the same spanwise 
and chordwise location. The spoiler surfaces were tested on a 1.5 aspect ratio, rectangular semispan wing model. Previously determined flutter boundaries were available for a nearly identical wing model ${ }^{7}$ which had been tested in the Langley Transonic Dynamics Tunnel (TDT). This information served as a guide in conducting the present study. Also, other types of spoiler surfaces had been previously tested for their effect on flutter on the same wind-tunnel model utilized for this study. The results from this earlier test are presented in reference 8 .

A number of spoiler surface parameters were varied during this study. Spoiler planform height and width variations were tested at one location on the wing. Additionally, one spoiler geometry configuration was tested at three spanwise locations on the wing to determine the spoiler's effectiveness in suppressing flutter as a function of location on the wing surface. All spoilers were mounted at the 10 percent chord $(x / c=0.10)$ position on the wing surface. This paper describes the experimental effects determined for the spoiler surfaces tested, including an emphasis on the torsional instability encountered.

\section{Test_Apparatus}

\section{Wind Tunnel}

The experimental study was conducted in the NASA Langley Transonic Dynamics Tunnel (TDT) ${ }^{6}$. The TDT is specifically designed for studying aeroelastic phenomenon. The facility is a continuous circuit wind tunnel capable of testing at total pressures from about 0.1 to 1.0 atmospheres and over a Mach number range from zero to 1.2. The test section of the TDT is $16.0 \mathrm{ft}$ square with cropped comers. Testing can be conducted in the TDT using either air or a heavy gas (dichlorodifluoromethane) as the test medium. The heavy gas was utilized during this test. A unique safety feature of the TDT is a group of four bypass valves connecting the test section area (plenum) of the tunnel to the return $\mathrm{lcg}$ of the wind-tunnel circuit. In the event of a model instability, such as flutter, these quick-actuating valves are opened. This causes a rapid reduction in the test section Mach number and dynamic pressure which may result in stabilizing the model.

\section{Model}

Wing.- The wind-tunnel wing model consisted of a relatively rigid wing surface which was integrally connected to a rectangular flexible support beam at the root of the wing. The wing had zero sweep and a 1.5 panel aspect ratio. The airfoil was a NACA 64A010 symmetrical shape. The construction of the wing is shown in figure 1 . The wing stiffness was provided by a flat 0.25 -inch thick aluminum plate (figure 2 ) which was covered by balsa wood to provide the airfoil shape while minimizing the weight. The aft 40 percent of the wing chord contained 49 1.375-inch holes drilled through the aluminum plate in order to reduce the weight of the wing and to shift the center of gravity of the wing forward to a chordwise position more representative of a typical wing. The wing aluminum plate was rounded at the leading edge and tapered at the trailing edge to meet the airfoil shape. A semicircular arc wing-tip shape constructed from balsa wood was bonded to the wing to smooth the aerodynamic environment of the wing tip. The rectangular support beam extended from the wing root at the 30 percent chord location to provide the flexibility needed to test the model to flutter. This beam section consisted of a $0.25^{\prime \prime}$ thick aluminum core cut from the same plate as the wing structure with two $0.0625^{\prime \prime}$ thick aluminum plates bonded and riveted to both sides. The thin plates extended over a portion of the wing plate to relieve stress concentrations at the wing root. The bond material resulted in a total thickness of $0.391^{\prime \prime}$. The support beam was $2.25^{\prime \prime}$ wide and was $11.33^{\prime \prime}$ long from the wing root to the windtunnel wall suppor. The support beam was cantilevered at the tunnel wall on a tumtable to allow remote control of the wing angle of altack during testing. A splitter plate was mounted at the wing root to provide a symmetry reflection plane for the wing aerodynamics. Sufficient clearance was provided between the splitter plate and the wing root and support shaft to prevent contact during testing.

Speilers.- The spoiler surfaces consisted of rectangular plates which were attached directly to the top and bottom of the wing. Figure 3 shows the manner in which the spoiler surfaces were actually attached to the wing plate. The spoiler surfaces were constructed from 0.05 " thick aluminum plate. Figure 4 is a line drawing representing the shape and orientation of the spoiler surfaces when mounted on the wing. The dashed lines in the planform view (figure 4) indicate optional locations for mounting and testing the spoiler surfaces. Rectangular segments of balsa wood were removed at each of these position options so that the spoilers could be mounted to the wing. Dummy weights were available for each of the possible test configurations so that the total weight and weight distribution of the model always remained the same regardless of the spoiler configuration being tested. The idea behind this was that the structural and inertial properties of the model would be essentially constant for all configurations so that any aeroelastic stability changes would be purely a function of aerodynamic changes. The gaps in the wing surface (where the balsa wood was removed for the spoiler mounting slots) were covered with aluminum tape to help smooth the wing aerodynamically.

Several variations in the geometric dimensions of the spoiler surfaces were tested during the wind-tunnel test. 
Spoiler vertical height and width (spanwise) variations were tested at $x / c=0.10, \eta=0.67$ (see figure 4 ). The spoiler heights $\left(h_{S}\right)$ available for testing at this location were $0.25^{\prime \prime}, 0.50^{\prime \prime}, 0.75^{\prime \prime}$, and $1.00 "$. The spoiler width variations were 5,10 , and 15 percent of the wing semispan ( $w=1.5^{\prime \prime}, 3.0^{n}$, and $4.5^{\prime \prime}$, respectively).

For the $h_{s}=0.50 ", w=3.0 "$ spoiler, variations were made in the spanwise location on the wing surface. Three mounting positions were available for the spanwise variations along the $x / c=0.10$ chord of the wing. These positions corresponded to $\eta=0.45,0.67$, and 0.90 as the point at which the spoiler was centered spanwise. A summary of the spoiler configurations tested is presented in table 1.

\section{Test Procedures}

\section{Ground Vibration Test}

A ground vibration study was conducted on the windtunnel model to determine its natural frequencies and to locate modal node lines. The model was excited by an impulse air shaker to minimize distorting the modes. A lightweight roving accelerometer was used to locate the node lines of the natural vibration modes while exciting the model with the impulse air shaker.

Measured node lines determined during the ground vibration test of the model prior to the addition of the spoiler surfaces are shown in figure 5 . Node lines measured following the addition of the spoilers were very similar to the experimental node lines shown in figure 5 . Table 2 contains the measured natural frequencies of the first five vibration modes of the model.

\section{Wind-Tunnel Test}

The flutter boundary for the model was approached in two manners during the wind-tunnel test. These two test procedures are shown in figure 6 . The first method was to begin testing at a specific Mach number and at a low dynamic pressure (relative to the predicted flutter dynamic pressure). Incremental increases in the dynamic pressure were then made at a constant Mach number to approach the flutter boundary. The second method involved testing along a near-constant stagnation pressure line in the windtunnel operating boundary. This technique is more time efficient in terms of tunnel operations. Throughout this experiment, the model was tested at a near zero angle-ofattack. Small changes in the angle-of-attack were made during the test so that the weight of the model was relieved (zero-g condition).

\section{Analytical Tools}

Several analytical computer programs were used to design the TDT flutter model. The results of these analyses also served as a guide in conducting the windtunnel test. Structural dynamic properties of the model prior to the addition of the spoiler surfaces were calculated using the Engineering Analysis Language (EAL) finiteelement-program package ${ }^{9}$. Two-dimensional-plate elements were used to simulate the structural properties of the aluminum plate in the model. A drawing indicating the clement arrangement developed in the finite element model is shown in figure 7 . The elements of the flexible support beam and the area of increased thickness on the wing plate were modeled with aluminum properties for a thickness of $0.391 "$. The remainder of the wing from the leading edge to the 60 percent chord position was modeled as aluminum with a thickness of $0.25 "$. The trailing edge region of the finite element model was simulated by $0.25^{\prime \prime}$-thick plate elements with reduced values of Young's modulus of elasticity and density (compared to aluminum) to account for the holes drilled through the plate in this region. Also, the trailing edge elements were shortened by 0.4 " in the flow direction (in comparison to the physical model) to make allowance for the trailing edge taper in the aluminum plate. Nonstructural mass was added to the model to account for the weight of the balsa wood. EAL was used to calculate natural frequencies, mode shapes, and generalized mass properties for the flutter model. Figure 5 shows the comparison between calculated and measured node lines for four primary vibration modes graphically. The comparison is good for all four modes. Table 2 presents calculated frequencies and shows the comparison between the calculated modal frequencies (calculations prior to addition of spoiler surfaces) and the measured values with the spoilers mounted on the wing. Although the calculations did not include the added weight of the spoilers, the comparison with the experimental frequencies is good. This indicates that the spoilers had only small effects on the natural vibration characteristics of the basic wing.

Calculated mode shapes and generalized masses and experimentally measured natural frequencies were then used in a flutter analysis software system, known as FAST $^{10}$, to calculate the flutter properties of the model prior to the addition of the spoiler surfaces. FAST was used to calculate unsteady aerodynamic forces based on geometry and structural dynamic properties using planar subsonic kernel function lifting-surface theory. Flutter instabilities were calculated using the $k$ method ${ }^{11}$. The only available analytical results are for the clean wing configuration without the spoiler weights. Therefore, to compare the results with experimental results without additional analyses, the present clean-wing analyses were adjusted by the ratio of the first torsional mode frequencies (measured) to obtain estimated analytical flutter values for 
the clean wing with the spoiler weights added. This technique was used for the same basic wing model in an earlier study ${ }^{8}$ and provided good correlation between analysis and experiment. The basis for this correction to the analytical results is that the spoilers add litule weight and stiffness to the basic wing so that the differences to the basic wing flutter can be primarily accounted for by the small change in the first torsional mode natural frequency.

\section{Results and Discussion}

Tests have been conducted in the TDT on a low. aspect-ratio, rectangular wing model to study the effects of spoilers on wing flutter. Results have been obtained for spoiler height and spoiler width variations. Spoiler location effects have also been researched by lesting one spoiler geometry at three spanwise locations along the 10 percent chord $(x / c=0.10)$ position.

Spoiler height effects.- Figure 8 indicates the effects of varying spoiler height (above the wing aerodynamic surface). Some of the experimental instability conditions are also presented in Table 3. The primary objective of this research at the outset was to determine the flutter suppressing capability of spoiler surfaces such as tested in this study. Figure $8 \mathrm{a}$ gives insight into the flutter suppression capability of spoiler surfaces as a function of spoiler height. As the spoiler height is increased, there appears to be a stabilizing effect on the flutter condition of the model for conditions below a Mach number of approximately 0.7 . For the $0.25^{\prime \prime}$ and $0.50^{\prime \prime}$ spoiler heights, this stabilizing trend is even more dramatic at transonic Mach numbers. But for spoiler heights greater than $0.50^{\prime \prime}$, this trend in the transonic range did not continue. In fact, a new instability was excited which does not appear to be classical flutter as was experienced at previously discussed conditions. The new instability appears to be a nearly single-degree-of-freedom torsional instability which is highly Mach number dependent and was found to occur at dynamic pressure conditions far below the expected flutter condition. The motion in this torsional instability appeared to be very similar to the wind-off first torsional mode of the wing. As the Mach number was decreased, the instability tended to transform from the torsional instability to the classical flutter instability in which the motion is primarily a coupling of the wing first bending mode and the wing first torsion mode. Figure $8 \mathrm{~b}$ provides a further indication, based on instability frequency, that these observations quantify the behavior of the model due to the spoiler surfaces. The $0.0{ }^{\prime \prime}, 0.25^{\prime \prime}$, and $0.50^{\prime \prime}$ cases shown in figure $8 \mathrm{~b}$ indicate slight variations in the instability frequency measured. This frequency is between the coupling modes of the flutter condition as previously described. But for the $0.75^{\prime \prime}$ and $1.00^{\prime \prime}$ spoilers, figure $8 \mathrm{~b}$ shows a dramatically increasing instability frequency as Mach $\mathrm{n}_{\mathrm{L}}$ increased. This frequency rapidly approaches the wir first torsion mode frequency. This behavior is supp. of the observation that this Mach number-depe! :ent instability is a single-degree-of-freedom tors nai instability.

Spoiler width effects.- Figure 9 shows the effects of varying spoiler width. Figures $9 \mathrm{a}-\mathrm{b}$ provide the same type of flutter trends as shown in figures 8a-b. The results in figure 9 show that as the spoiler width is increased the torsional instability predominates the flutter condition at higher Mach numbers. The experimental instability conditions for the spoiler width variations are shown in table 4.

Torsional instability.- The cause of this torsional instability has not been determined based on the experimental results, but a number of possible influences are suggested in related literature ${ }^{12,13}$. Perhaps the most likely cause is a periodicity of vortex shedding related to the Strouhal number occurring about the spoiler surfaces which drives the model in the first torsion mode. In reference 12 , a nondimensional Strouhal number is presented for a number of two-dimensional bodies based on the projection of the body in the vertical plane perpendicular to the flow. Reference 12 indicates that vortex shedding occurs around cylinders for a Strouhal number of 1.2 or higher for the range of Reynolds number of interest to the current study. A number of other studies summarized in reference 12 showed that the wing-wake frequency response developed for a range of Strouhal numbers (based on frequency in units of radians/seconds) from 0.93 to 1.32 for two-dimensional flat plates and airfoils.

Tables 3 and 4 show instability results obtained during the present study, including a calculated value of the Strouhal number for each case in which a measured value of the instability frequency was available. The Strouhal number calculated in table 3 is based on the total projection of the spoiler surfaces in the vertical direction perpendicular to the freestream flow. In other words, the Strouhal number is based on the sum of the upper surface spoiler's projection above the wing surface, the wing thickness at the chordwise location of the spoiler, and the lower surface spoiler's projection below the wing surface. Based on this dimension, the Strouhal number for the torsional instability was between $S_{h}=0.049$ and 0.055 for configuration 5 and between $S_{h}=0.038$ and 0.044 for configuration 6 . The Strouhal number for the cases in table 4 were calculated based on the spoiler's width along the span of the wing. In these cases, only configuration 2 exhibited the torsional instability. The Strouhal number for the torsional instability cases with configuration 2 was nearly constant with an average Strouhal number of $S_{w}=0.068$. Obviously, the Strouhal number for all of the 
measured conditions in the current study is far below the values presented above from reference 12 and appear to discount the possibility of the torsional instability being excited by shedding vortices.

Spoiler location effects.- A very limited examination of the effect of spoiler location on flutter was conducted with the $0.5^{\prime \prime}$ high, $3.0^{\prime \prime}$ wide spoiler configuration. This spoiler size was tested at each of the spoiler span locations indicated in figure 4. More data were obtained at the center location because this configuration was used for both the spoiler width and the spoiler height variations. The results obtained from varying the spanwise location of the spoilers are shown in figure 10. For the spoilers located at 45 percent and at 90 percent of the wing semispan (see figure 4), flutter points were only obtained at $M=0.7$ and 0.85 . These data show little or no significant effect on the flutter of the model based on these spoiler locations.

Elutter analysis.- The FAST aeroelastic software system was used to calculate the flutter conditions of the basic wing prior to the addition of the spoiler surfaces. This analysis of the clean wing was adjusted by utilizing the ratio of the measured first torsional mode natural frequencies. A comparison between the adjusted analysis and the experimental flutter boundary for the clean wing with the simulated weight of all the spoilers added is shown in figure 11. The results show that there is good correlation between the analysis and the experiment. This indicates that a good analytical model exists which could be used for further flutter analysis and study of the torsional instability.

\section{Concluding Remarks}

An experimental study has been conducted to determine the effectiveness of vertical spoiler surfaces located on the 10 percent chord in suppressing flutter onset for a 1.5 panel aspect ratio, rectangular wing windtunnel model. The study included variations in the spoiler geometry (height and width) and location (spanwise) on the wing surface. Flutter analysis was conducted for the basic wing.

The wind-tunnel test showed that slight increases in the flutter dynamic pressure conditions were obtained due to the spoiler surfaces at subsonic Mach numbers. This effect at subsonic Mach numbers demonstrated consistent trends in that increasing spoiler dimensions (either height or width) resulted in increasing flutter dynamic pressures. The largest spoiler surfaces tested for either height or width variations resulted in approximately 15 percent increases in the flutter dynamic pressures at subsonic conditions.
At transonic Mach numbers, much larger increases in the flutter dynamic pressure were experienced for the smaller size spoilers tested indicating that they were very effective in suppressing flutter. On the other hand, several of the larger size spoiler surfaces induced a torsional instability in this Mach number range. This detrimental torsional instability was extremely Mach number sensitive and was found to occur at dynamic pressure conditions well below the expected flutter dynamic pressures.

A limited amount of experimental data were obtained to examine the effect of spanwise location of the spoiler surfaces on flutter. For the three spanwise locations tested in this study, no measurable effect of spoiler location was found.

Analytical flutter predictions were made using subsonic lifting surface theory for the basic wing prior to the addition of the spoiler surfaces. This analysis of the clean wing was adjusted by utilizing the ratio of the measured first torsional mode natural frequencies. The adjusted analysis correlated well with the experimental results.

\section{Beferences}

1) Ruhlin, Charles L.; Watson, Judith J.; Ricketts, Rodney H.; and Doggett, Robert V., Jr.: Evaluation of Four Subcritical Response Methods for On-line Predictions of Flutter Onset in Wind-Tunnel Tests. AIAA Paper No. 82-0644, 1982.

2) Ricketts, Rodney H.; Doggett, Robert V., Jr.: WindTunnel Experiments on Divergence of Forward-Swept Wings. NASA TP-1685, 1980.

3) Noll, Thomas E.; Perry, Boyd III; et al: Aeroservoelastic Wind-Tunnel Investigations Using the Active Flexible Wing Model - Status and Recent Accomplishments. AIAA Paper No. 89-1168, 1989.

4) Mabey, D. G.; Ashill, P. R.; and Welsh, B. L.: Aeroelastic Oscillations Caused by Transitional Boundary Layers and Their Attenuations. Journal of Aircraft, Vol. 24, No. 7, 1987.

5) Cole, Stanley R.: Exploratory Flutter Test in a Cryogenic Wind Tunnel. NASA TM-86380, 1985.

6) Reed, Wilmer H.: Aeroelasticity Matters: Some Reflections of Two Decades of Testing in the NASA Langley Research Tunnel. NASA TM-83210, 1981.

7) Cole, Stanley R.: Flutter of a Low-Aspect-Ratio Rectangular Wing. NASA TM-4116, 1989. 
8) Doggett, Robert V., Jr.: Some Effects of Aerodynamic Spoilers on Wing Flutter. NASA TM101632, 1989.

9) Whetstone, W. D.: EISI-EAL Engineering Analysis Language Reference Manual. Engineering Information Systems, Inc., 1983.

10) Desmarais, Robert N.; and Bennett, Robert M.: User's Guide for a Modular Flutter Analysis Software System (FAST Version 1.0). NASA TM$78720,1978$.

11) Desmarais, Robert N.; and Bennett, Robert M.: An Automated Procedure for Computing Flutter Eigenvalues. Journal of Aircraft, Vol. 11, No. 2, 1974.

12) Fung, Y. C.: Aeroelasticity. Dover Publications, Inc., New York, 1969.

13) Scanlan, Robert H.; and Rosenbaum, Robert: Aircraft Vibration and Flutter. Dover publications, Inc., New York, 1968.

Table 1: Summary of spoiler configurations tested.

\begin{tabular}{|c|c|c|c|c|}
\hline Configuration & $\begin{array}{c}\text { Height, } \\
\text { in }\end{array}$ & $\begin{array}{c}\text { Width, } \\
\text { in }\end{array}$ & $\mathrm{x} / \mathrm{c}$ & $\eta$ \\
\hline \hline 1 & 0 & 0 & 0.1 & 0.67 \\
2 & 0.50 & 4.5 & 0.1 & 0.67 \\
3 & 0.50 & 3.0 & 0.1 & 0.67 \\
4 & 0.50 & 1.5 & 0.1 & 0.67 \\
5 & 1.00 & 3.0 & 0.1 & 0.67 \\
6 & 0.75 & 3.0 & 0.1 & 0.67 \\
7 & 0.25 & 3.0 & 0.1 & 0.67 \\
8 & 0.50 & 3.0 & 0.1 & 0.45 \\
9 & 0.50 & 3.0 & 0.1 & 0.90 \\
\hline
\end{tabular}

Table 2. Calculated and measured natural frequencies.

\begin{tabular}{|l|c|c|}
\hline \multirow{2}{*}{$\begin{array}{c}\text { Vibration } \\
\text { mode }\end{array}$} & \multicolumn{2}{|c|}{ Natural frequencies, $\mathrm{Hz}$} \\
\cline { 2 - 3 } & Measured & Calculated** \\
\hline 1- First bending & 2.85 & 3.16 \\
2- First torsion & 13.1 & 14.4 \\
3- In-plane & 15.5 & - \\
4- Second bending & 26.2 & 24.1 \\
5- Second torsion & 62.6 & 56.1 \\
\hline
\end{tabular}

** Calculations are based on the basic wing finite element model without spoilers.
Table 3. Experimental results for spoiler height variations.

\begin{tabular}{|c|c|c|c|c|}
\hline Configuration & $\mathbf{M}$ & $\mathrm{q}, \mathrm{lb} / \mathbf{f t}^{2}$ & $\mathbf{f}, \mathbf{H z}$ & $\mathbf{S}_{\mathbf{h}}$ \\
\hline \hline 1 & 0.60 & 111.5 & 7.13 & 0.025 \\
1 & 0.75 & 103.7 & 6.50 & 0.018 \\
1 & 0.90 & 97.7 & 4.76 & 0.011 \\
\hline 5 & 0.60 & 122.9 & 7.78 & 0.044 \\
5 & 0.68 & 122.4 & 8.13 & 0.041 \\
5 & 0.71 & 111.0 & 9.24 & 0.044 \\
5 & 0.72 & 90.0 & 10.11 & 0.049 \\
5 & 0.73 & 73.4 & 10.78 & 0.051 \\
5 & 0.71 & 70.6 & 10.81 & 0.052 \\
5 & 0.71 & 59.2 & 11.20 & 0.054 \\
5 & 0.72 & 46.9 & 11.63 & 0.055 \\
5 & 0.80 & 34.3 & 12.13 & 0.053 \\
\hline 6 & 0.60 & 117.6 & 7.34 & - \\
6 & 0.70 & 117.1 & 7.19 & 0.030 \\
6 & 0.77 & 116.6 & 7.79 & 0.030 \\
6 & 0.78 & 83.6 & 10.21 & 0.038 \\
6 & 0.77 & 55.9 & 11.21 & 0.044 \\
\hline
\end{tabular}

Table 4.- Experimental results for spoiler width variations.

\begin{tabular}{|c|c|c|c|c|}
\hline Configuration & $\mathbf{M}$ & $\mathrm{q}, \mathbf{l b} / \mathbf{f t}^{2}$ & $\mathbf{f}, \mathbf{H z}$ & $S_{W}$ \\
\hline 2 & 0.60 & 119.5 & 7.50 & 0.059 \\
2 & 0.66 & 118.9 & 7.38 & 0.052 \\
2 & 0.75 & 112.7 & 8.75 & 0.055 \\
2 & 0.77 & 88.4 & - & - \\
2 & 0.81 & 64.5 & 11.25 & 0.068 \\
2 & 0.79 & 63.2 & 11.25 & 0.068 \\
2 & 0.82 & 50.4 & 11.50 & 0.067 \\
\hline 3 & 0.60 & 115.1 & 7.23 & 0.038 \\
3 & 0.67 & 113.4 & 6.96 & 0.033 \\
3 & 0.75 & 110.2 & 6.61 & 0.028 \\
3 & 0.79 & 109.0 & 6.60 & 0.026 \\
3 & 0.85 & 109.3 & 5.63 & 0.021 \\
3 & 0.88 & 127.5 & - & - \\
3 & 0.90 & 133.0 & 5.00 & 0.017 \\
\hline 4 & 0.60 & 113.1 & 7.13 & 0.019 \\
4 & 0.75 & 104.5 & 6.50 & 0.014 \\
4 & 0.82 & 98.1 & 5.88 & 0.011 \\
4 & 0.85 & 104.6 & 5.63 & 0.010 \\
\hline
\end{tabular}




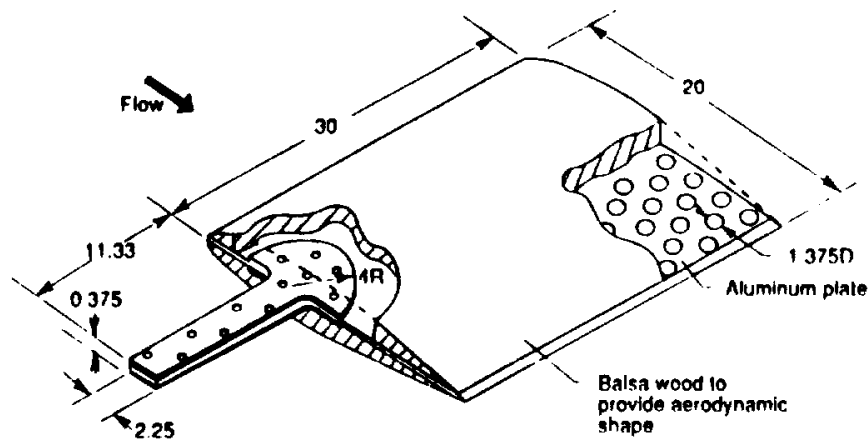

Fig. 1.- Culaway drawing showing wing model construction. Dimensions are given in inches.

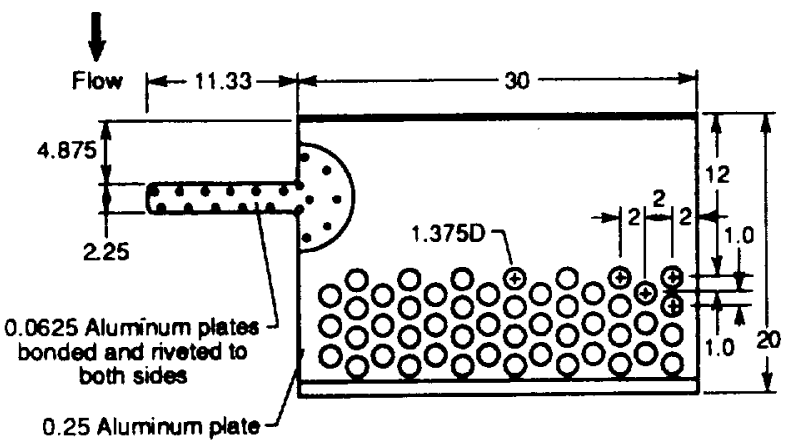

Fig. 2.- Aluminum plate construction. Dimensions are given in inches.

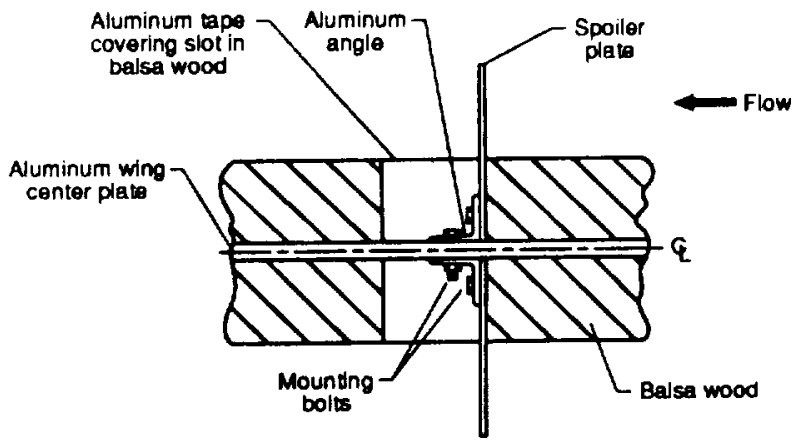

Fig. 3.- Cutaway drawing of end view of wing showing mounting technique used to attach spoiler plates to wing.

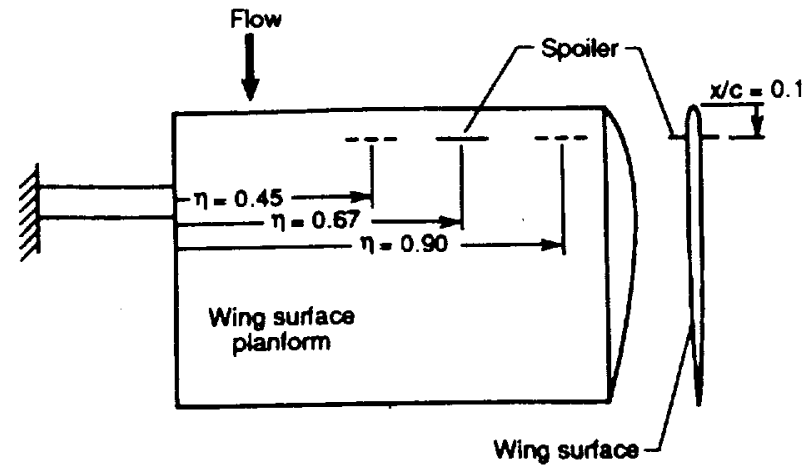

Fig. 4.- Planform and end view of spoilers mounted on wing. Dashed lines on planform view indicate additional spoiler mounting locations.

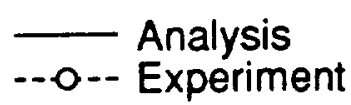

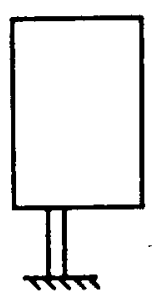

First bending

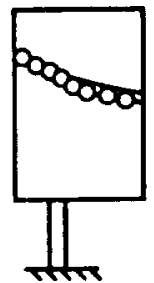

Second bending

Fig. 5.- Measured and calculated basic wing node lines. 


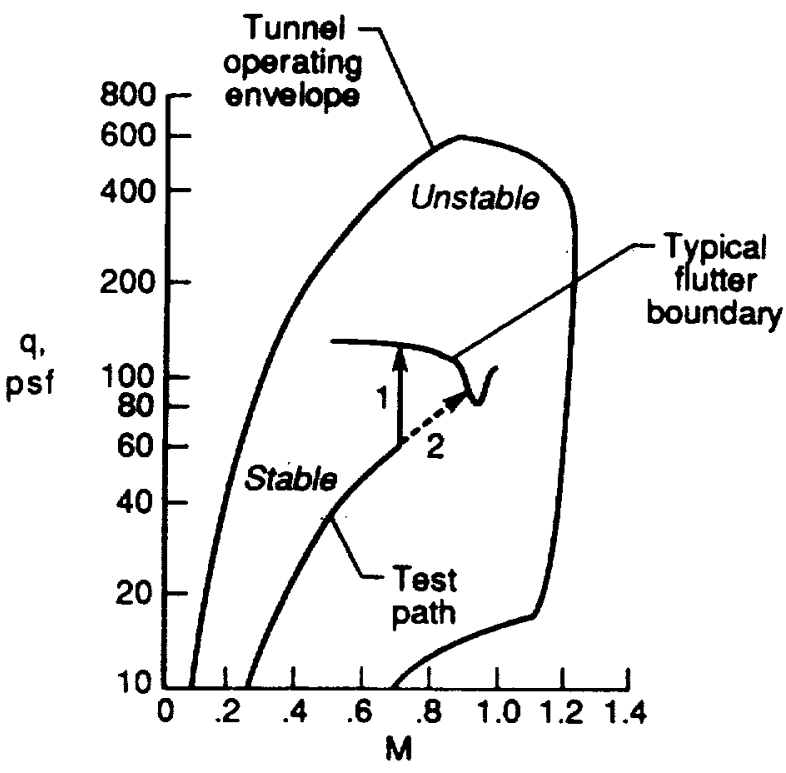

Fig. 6.- Flutter testing procedures used during the TDT test.

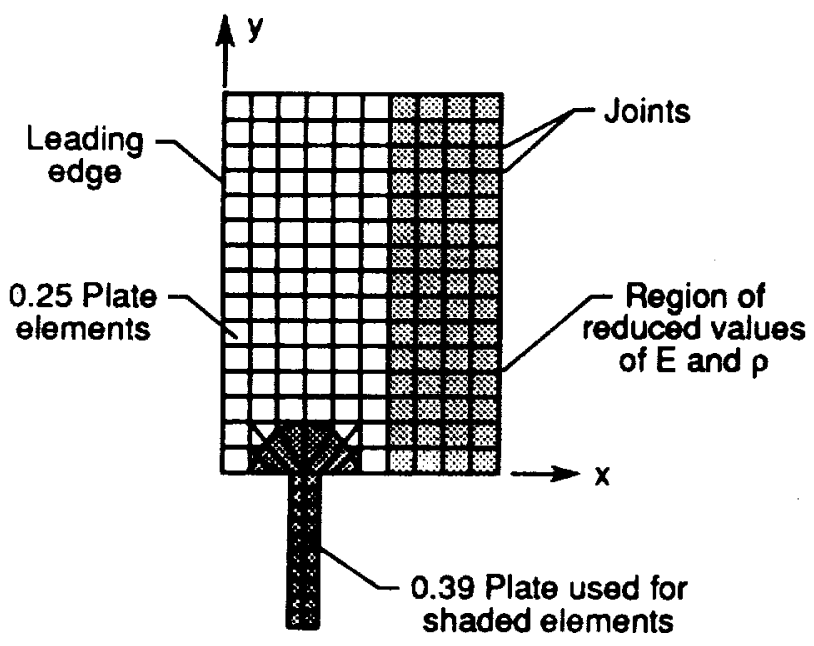

Fig. 7.- Finite element model. Dimensions are given in inches.

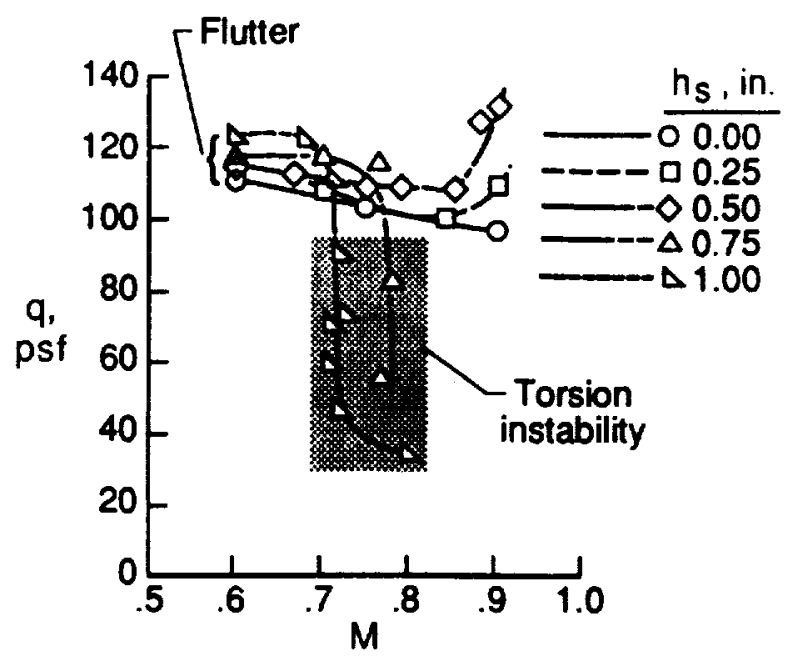

(a) Dynamic pressure versus Mach number

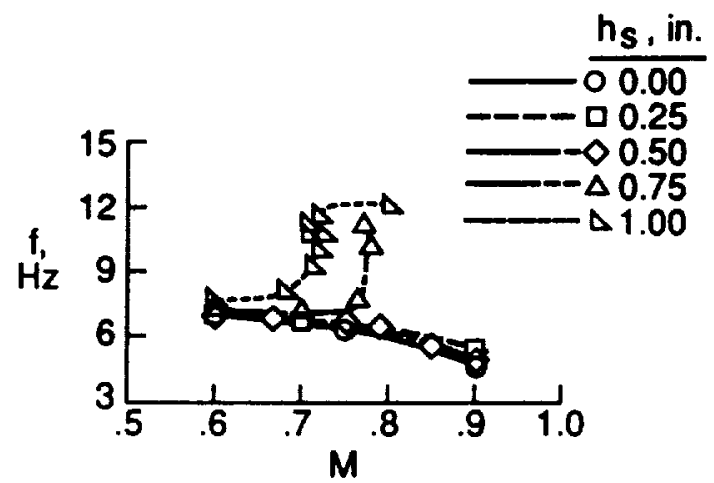

(b) Frequency versus Mach number

Fig. 8.- Experimental instability results for various spoiler heights $\left(w=3.0^{\prime \prime}\right)$. 


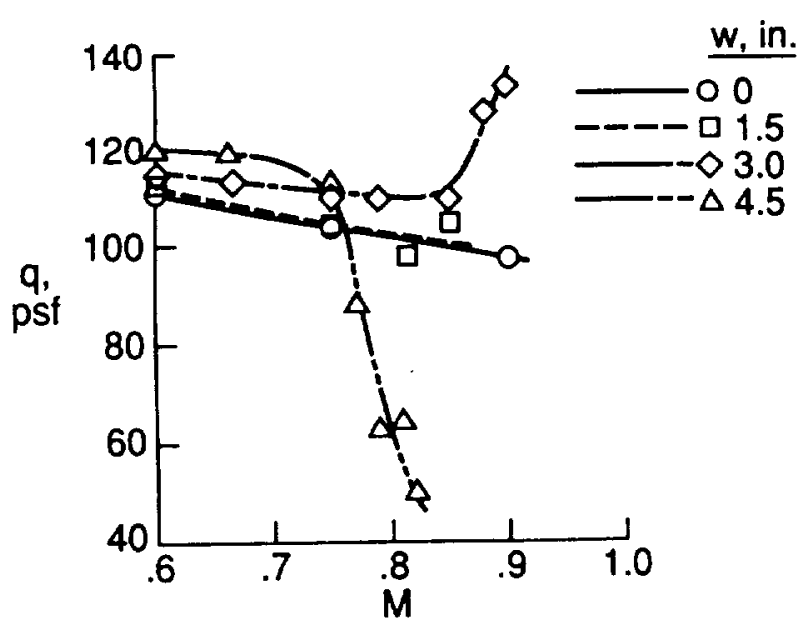

(a) Dynamic pressure versus Mach number

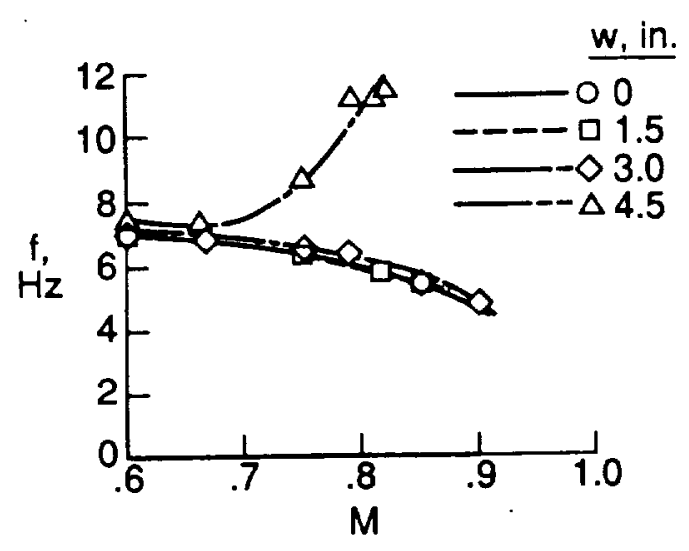

(b) Frequency versus Mach number

Fig. 9.- Experimental instability results for various spoiler widths $\left(\mathrm{h}_{\mathrm{S}}=0.5^{\prime \prime}\right)$.

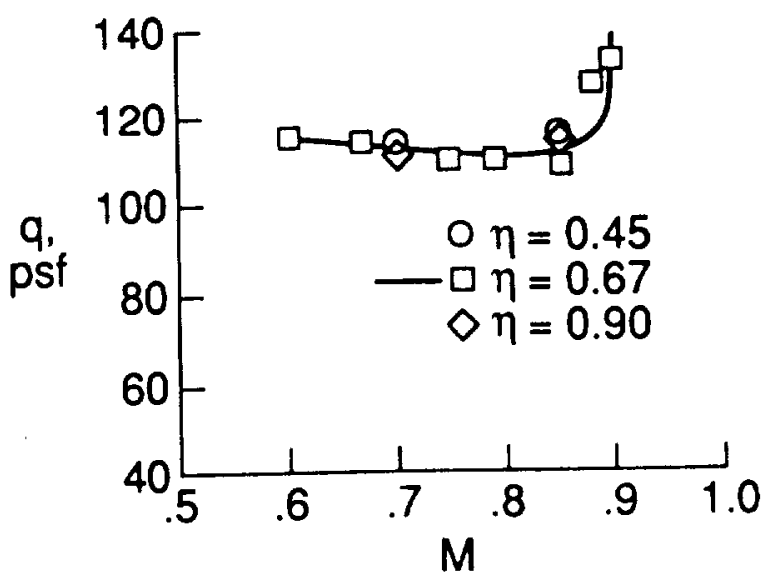

Fig. 10.- Effect of spoiler location along the wing span $\left(h_{S}=0.5^{\prime \prime}, w=3.0^{\prime \prime}\right)$.

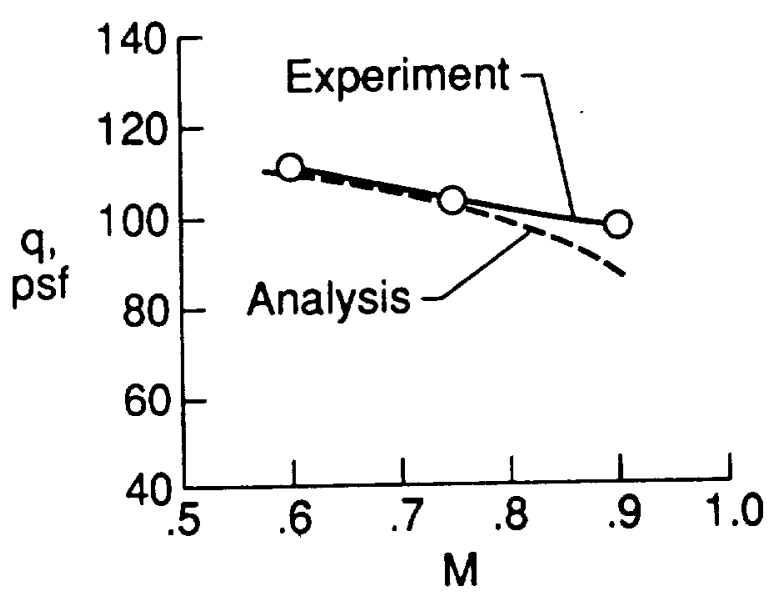

Fig. 11.- Experimental and calculated flutter boundaries for the basic wing with no spoiler surfaces. 


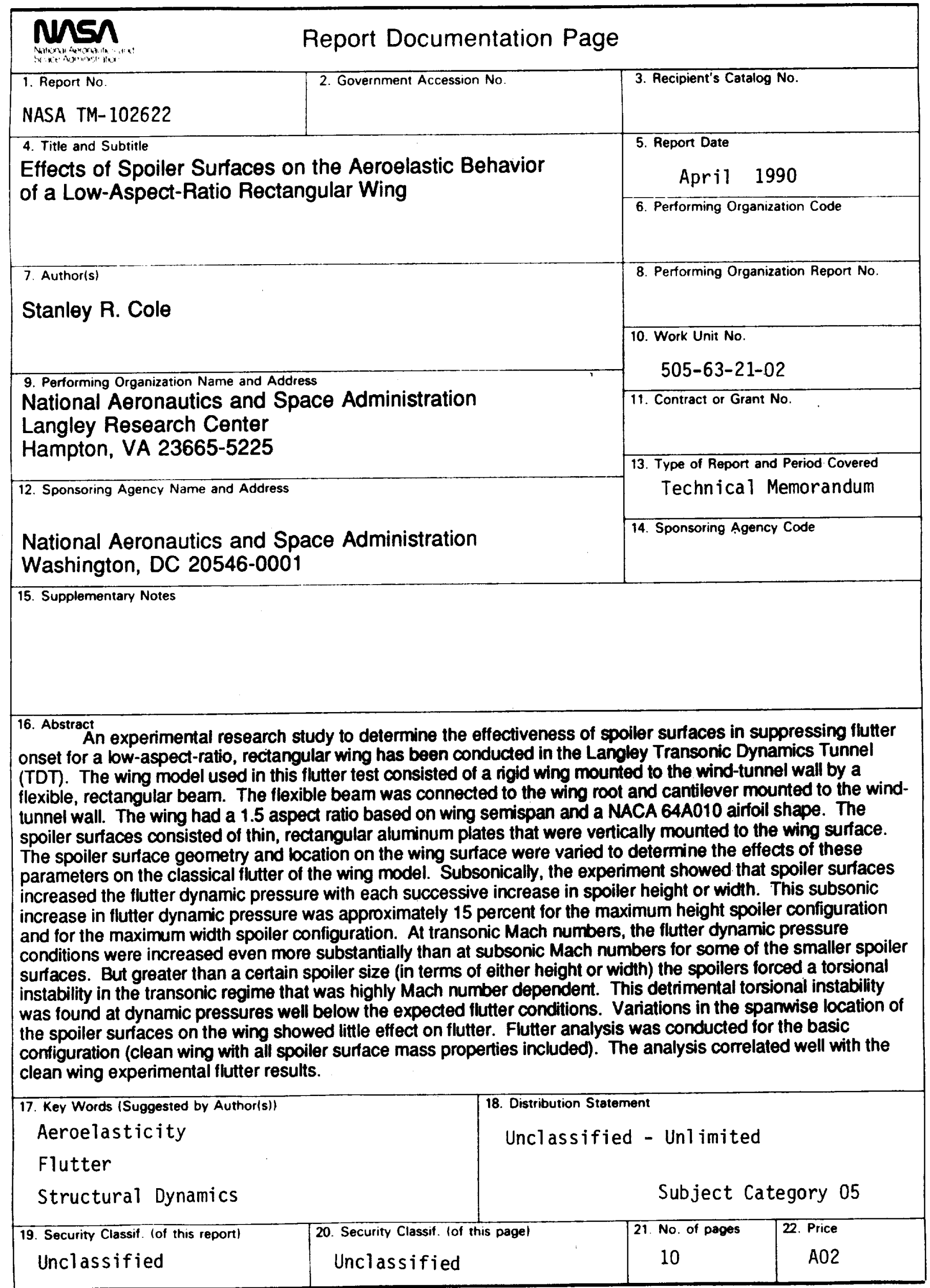

